\title{
High-Resolution Mass Spectrometry for the Comprehensive Characterization of Plant-Pigment-Based Tattoos and Dyes Formulations
}

\author{
Laura Rubio *(D), Carmen Garcia-Jares (D) and Marta Lores
}

Citation: Rubio, L.; Garcia-Jares, C.; Lores, M. High-Resolution Mass Spectrometry for the Comprehensive Characterization of

Plant-Pigment-Based Tattoos and Dyes Formulations. Cosmetics 2021, 8, 55. https://doi.org/10.3390/ cosmetics 8020055

Academic Editor: Enzo Berardesca

Received: 25 May 2021

Accepted: 16 June 2021

Published: 21 June 2021

Publisher's Note: MDPI stays neutral with regard to jurisdictional claims in published maps and institutional affiliations.

Copyright: (c) 2021 by the authors. Licensee MDPI, Basel, Switzerland. This article is an open access article distributed under the terms and conditions of the Creative Commons Attribution (CC BY) license (https:/ / creativecommons.org/licenses/by/ $4.0 /)$.
CRETUS, Department of Analytical Chemistry, Nutrition and Food Science, Universidade de Santiago de Compostela, E-15782 Santiago de Compostela, Spain; carmen.garcia.jares@usc.es (C.G.-J.); marta.lores@usc.es (M.L.)

* Correspondence: laura.rubio.lareu@usc.es; Tel.: +34-881-814-379
Abstract: There has been little research on emerging natural-pigment-based temporary tattoos and their constituents so far. This study focused on the characterization of natural henna and jagua tattoos and dyes in commercial samples. Sample manipulation and treatment were minimal to analyze natural pigments as they are marketed. The characterization of active compounds was performed by ultra-high-performance liquid chromatography coupled with quadrupole time-offlight mass spectrometry (UHPLC-QTOF-MS). A novel untargeted characterization was also applied for these types of samples, searching for compounds ranging from the original ingredients to other additives of interest they may contain. The fact that these products may also be a source of unlabelled allergens was considered. This work showed that not all of the 34 samples analyzed contained their characteristic active ingredients, and in addition, 70 substances of a different nature were found. Therefore, a rapid and high-throughput methodology has been developed for the identification of the components of these dyes, providing a necessary approach for quality control or identification of suspicious substances.

Keywords: henna; jagua; temporary tattoos; natural tattoo ingredients; dyes; high-performance liquid chromatography; quadrupole time-of-flight mass spectrometry

\section{Introduction}

Temporary tattoos have been widely used since ancient times for body decoration, but in recent years, they have become more popularized and fashionable substitutes for permanent ones. Some temporary tattoos use natural pigments, but little is known about them. This is the case of traditional henna tattoos, which have long been seen at festivals, holiday locations, street fairs and even medieval marketplaces. More recently, an interesting option has been placed on the market, an alternative dye for temporary tattoos called jagua, often sold on the Internet.

Natural henna (Lawsonia inermis) has a reddish-brown coloring [1] due to its active ingredient lawsone (2-hydroxy-1,4-naphthoquinone). Different formulations of black henna or even other more striking colors are now available in the market to be used as temporary dyes for henna tattoos. The components of henna tattoos are discussed in a recent article [2]. Regulations of natural-pigment-based temporary tattoos have not yet been formulated, and most of these commercial products of plant origin are not correctly or fully labeled. The safety of henna in products containing its extracts, such as temporary tattoos, has not been assessed. The methodology used for the determination of lawsone is high-performance liquid chromatography with diode array detection (HPLC-DAD), both in commercial henna products and in the tattooists' own preparations [3,4]. In these works, sample preparation is based on simple dilution, followed by sonication and final filtration before analysis. For centuries, henna has also been used as the most common 
natural hair dyeing and tattooing agent in many civilizations and cultures. On this point, the Scientific Committee on Consumer Safety (SCCS) has evaluated the safety of henna and its main active ingredient lawsone in hair dye products [5]. It concludes that the available information is sufficient to assess the safe use of henna as a hair dye, although in specific formulations.

Jagua has been used by indigenous tribes to stain the skin, but nowadays, it is becoming increasingly popular as a newer temporary tattoo. This natural pigment is obtained from a tropical fruit known as Genipa americana L. Jagua contains genipin and geniposide as its main active ingredients. There are already studies pointing to the fact that the jagua constituents in temporary tattoos may become potential new allergens [6,7]. In fact, a case of allergic contact dermatitis caused by a temporary jagua tattoo purchased over the Internet has already been reported [8]. Reverse-phase liquid chromatography coupled with ultraviolet (UV) detection identified genipin as the allergen involved in the reactions, and the presence of geniposide was also confirmed. However, there are no other studies on the determination of these two ingredients in real jagua samples; that is, there is no systematic methodology for their analysis. Jagua tattoos have not even been regulatorily considered yet, although their allergenic potential has already been documented, as mentioned above. Because of their recent emergence and lack of regulation, the safety of these new ingredients is highly questionable because of possible unknown reactions.

Both permanent and temporary tattoos can be included in the group of new-format cosmetics or considered as borderline products in the European regulation [9]. In particular, temporary tattoos have a diverse chemical composition and unclear legislation. According to the guidelines of the Manual of Borderline Products, they should be correctly labeled under the Cosmetics Regulation [10] and the Toys Directive [11]. However, for borderline products, the reality is far from complying with these requirements. Based on a recent study [12], the labeling of tattoo sticker samples is either non-existent or incorrect according to their ingredient content. Most of the commercial plant-origin products are not labeled.

This work was prompted by the lack of analytical methodology, regulation, labeling and general information on these natural, temporary henna and jagua tattoos. In a previous investigation, the simultaneous quantification by HPLC-DAD of their active ingredients was reported [13]. However, it already pointed to the need for a more in-depth study to try to provide a broader view of the composition of these beauty products. Regarding the labeling of the samples studied, although some products are formulated, the list of ingredients may not be complete, or extra ingredients (extracts, allergens, preservatives) may be present. Frauds and other problems in the composition of these types of samples have already been described [13]. It is important to note the non-existence of bibliographical data on the characterization of these types of samples.

Therefore, the present work is aimed towards the characterization of natural henna and jagua tattoos and dyes in a wide broad range of samples available on the market, both by a targeted and by a non-targeted approach. In addition to focusing on measurements of target compounds or characteristic features, recent advances in combining liquid chromatography (LC) with high-resolution mass spectrometry (HRMS) allow the simultaneous determination of many compounds in parallel and without prior knowledge of the sample constituents. The high analytical power provided by these HRMS instruments allows the screening of compounds of interest in complex natural matrices of diverse origin [14-16]. Then, ultra-high-performance liquid chromatography coupled with quadrupole time-of-flight mass spectrometry (UHPLC-QTOF-MS) will be used as a rapid and powerful methodology for the identification of the ingredients of natural tattoos and dyes, providing a necessary approach for quality control or identification of suspect substances. As far as we know, this is the first time that high-resolution analysis has been proposed for these types of samples. 


\section{Materials and Methods}

\subsection{Chemical and Reagents}

All reagents and solvents were of analytical grade. Genipin $\left(\geq 98 \%, \mathrm{C}_{11} \mathrm{H}_{14} \mathrm{O}_{5}\right)$ was obtained from Biosynth Carbosynth (Berkshire, United Kingdom), geniposide ( $98 \%$, $\left.\mathrm{C}_{17} \mathrm{H}_{24} \mathrm{O}_{10}\right)$ from Sigma Aldrich (Steinheim, Germany), and lawsone $\left(>98 \%, \mathrm{C}_{10} \mathrm{H}_{6} \mathrm{O}_{3}\right)$ was acquired by AlfaAesar (Karlsruhe, Germany). For mobile phase preparation, MS-grade methanol provided by Sigma-Aldrich Chemie $\mathrm{GmbH}$, ultrapure water MS-grade purchased by Scharlab (Barcelona, Spain) and formic acid obtained by Merck (Darmstadt, Germany) were used.

Individual stock solutions of each compound were prepared in methanol. Further dilutions and mixtures were obtained by convenient dilution of the stock solution in methanol. All solutions were stored in glass vials protected from light and kept in a freezer at $-20{ }^{\circ} \mathrm{C}$.

\subsection{Samples}

Tattoo samples comprised 17 henna tattoos (HT) and 6 jagua tattoos (JT). Additionally, 10 samples of henna hair dyeing were included in the study. Three of the latter were also claimed for use as temporary body decoration (HTD). Samples were acquired through a well-known site available to anyone on the Internet. They were provided by different sellers, and some were sorted into sets. Two hennas labeled as Pakistani origin were collected from a local source in Morocco. In total, 27 hennas and 6 jaguas available at the time of acquisition were included. In addition, the plant origin sample labeled as herbaceous plant tattoo (HPT) was also purchased online, for which the composition and source species are unknown. The total number of samples reached 34. The color, sample type, set, labeled ingredients and other comments on the label are detailed in Table 1. Samples were kept in their original containers protected from light at room temperature until analysis.

Table 1. Characteristics of the analyzed samples. HT: Henna Tattoo; HD: Henna Dye, HTD: Henna Tattoo-Dye; JT: Jagua tattoo; HPT: Herbaceous Plant Tattoo.

\begin{tabular}{|c|c|c|c|c|c|}
\hline $\begin{array}{l}\text { Sample } \\
\text { Code }\end{array}$ & Color/Aspect & $\begin{array}{l}\text { Sample } \\
\text { Type }\end{array}$ & Set & $\begin{array}{c}\text { Labeled } \\
\text { Ingredients }\end{array}$ & Additional Information Available in Label/Internet \\
\hline HT-1 & & \multirow{9}{*}{ Paste } & \multirow{9}{*}{1} & \multirow{9}{*}{ None } & \multirow{9}{*}{$\begin{array}{l}\text { 100\% VEG, Indian origin, does not contain PPD, clinically } \\
\text { tested. }\end{array}$} \\
\hline HT-2 & & & & & \\
\hline HT-3 & & & & & \\
\hline HT-4 & & & & & \\
\hline HT-5 & & & & & \\
\hline HT-6 & & & & & \\
\hline HT-7 & & & & & \\
\hline HT-8 & & & & & \\
\hline HT-9 & & & & & \\
\hline
\end{tabular}


Table 1. Cont.

\begin{tabular}{|c|c|c|c|c|c|}
\hline $\begin{array}{l}\text { Sample } \\
\text { Code }\end{array}$ & Color/Aspect & $\begin{array}{l}\text { Sample } \\
\text { Type }\end{array}$ & Set & $\begin{array}{c}\text { Labeled } \\
\text { Ingredients }\end{array}$ & Additional Information Available in Label/Internet \\
\hline HT-10 & & \multirow{3}{*}{ Paste } & \multirow{3}{*}{2} & \multirow{3}{*}{ None } & \multirow{3}{*}{ 100\% VEG, Indian origin. } \\
\hline HT-11 & & & & & \\
\hline HT-12 & & & & & \\
\hline HT-13 & & \multirow{2}{*}{ Paste } & \multirow{2}{*}{3} & \multirow{2}{*}{ None } & \multirow{2}{*}{ Pakistani origin. } \\
\hline HT-14 & & & & & \\
\hline HT-15 & & \multirow{3}{*}{ Paste } & \multirow{3}{*}{4} & \multirow{3}{*}{ None } & \multirow{3}{*}{$\begin{array}{l}100 \% \text { an ayuverdic and non-allergic medicated, mehndi } \\
\text { with fruit and flower. Keep in cool, dry, and dark place. } \\
100 \% \text { VEG, Indian origin. }\end{array}$} \\
\hline HT-16 & & & & & \\
\hline HT-17 & & & & & \\
\hline HTD-1 & & Powder & - & Lawsonia inermis & $\begin{array}{c}100 \% \text { natural and pure, with } 0 \% \text { additives, } 0 \% \text { chemicals } \\
\text { and no added dyes. Marrakech origin. Tips on how to use } \\
\text { on hair. }\end{array}$ \\
\hline HTD-2 & & \multirow{2}{*}{ Powder } & \multirow{2}{*}{5} & Fresh henna leaves & \multirow{2}{*}{$\begin{array}{l}100 \% \text { pure and natural, no chemicals, preservatives, or } \\
\text { pesticides, cruelty-free, parabens-free, vegan. Directions to } \\
\text { use on hair, application, how to store. This product has been } \\
\text { certified by the National Program for Organic Production, } \\
\text { India Organic and USDA Organics. Best before: March } 2022 \text {. }\end{array}$} \\
\hline HTD-3 & & & & Henna and Indigo & \\
\hline HD-1 & & \multirow{6}{*}{ Powder } & \multirow{6}{*}{6} & $\begin{array}{l}\text { Henna plant } \\
\text { powder (Lawsonia } \\
\text { inermis), Juglans } \\
\text { regia, Cassia obovata }\end{array}$ & \multirow{6}{*}{$\begin{array}{l}\text { Green product. Vegan. Free of ammonia, PPD and metal } \\
\text { salts. }\end{array}$} \\
\hline HD-2 & & & & $\begin{array}{l}\text { Indigofera tinctoria, } \\
\text { Lawsonia inermis }\end{array}$ & \\
\hline HD-3 & & & & $\begin{array}{l}\text { Indigofera tinctoria, } \\
\text { ferrous sulfate, } \\
\text { Haematoxylon } \\
\text { campechianum, } \\
\text { Cassia obovata }\end{array}$ & \\
\hline HD-4 & & & & $\begin{array}{l}\text { Cassia obovata, } \\
\text { Lawsonia inermis, } \\
\text { sodium picramate }\end{array}$ & \\
\hline HD-5 & & & & Lawsonia inermis & \\
\hline HD-6 & & & & $\begin{array}{l}\text { Cassia obovata, } \\
\text { Curcuma longa, } \\
\text { Chamomilla recutita }\end{array}$ & \\
\hline
\end{tabular}


Table 1. Cont.

\begin{tabular}{|c|c|c|c|c|c|}
\hline $\begin{array}{l}\text { Sample } \\
\text { Code }\end{array}$ & Color/Aspect & $\begin{array}{l}\text { Sample } \\
\text { Type }\end{array}$ & Set & $\begin{array}{c}\text { Labeled } \\
\text { Ingredients }\end{array}$ & Additional Information Available in Label/Internet \\
\hline HD-7 & & Powder & - & $\begin{array}{l}\text { Lawsonia inermis } \\
\text { (henna) leaf } \\
\text { powder, Indian } \\
\text { gooseberry (Amla), } \\
\text { Soapnut (Ritha), } \\
\text { Acacia concina } \\
\text { (Shikakai), Bacopa } \\
\text { monnieri (Brahmi), } \\
\text { False daisy } \\
\text { (Bhringraj) }\end{array}$ & $\begin{array}{l}100 \% \text { natural and pure. Cruelty-Free. No pesticides, no } \\
\text { chemicals, and dyes. Does not contain ammonia, peroxides, } \\
\text { PPD, heavy metals and other harmful compounds. For } \\
\text { external use only, directions for use. Indian origin. }\end{array}$ \\
\hline JT-1 & & Paste & - & $\begin{array}{c}\text { Genipa americana } \\
\text { fruit juice, xanthan } \\
\text { gum, citric acid, } \\
\text { potassium sorbate, } \\
\text { Lavandula } \\
\text { angustifolia flower } \\
\text { oil, limonene, } \\
\text { linalool }\end{array}$ & Non tested on animals, non-toxic, PPD free, latex free. \\
\hline JT-2 & & Paste & - & $\begin{array}{l}\text { Water, alcohol } \\
\text { denat, Genipa } \\
\text { americana, xanthan } \\
\text { gum, citric acid, } \\
\text { potassium sorbate }\end{array}$ & $100 \%$ Natural, for external use only. \\
\hline JT-3 & & Paste & - & $\begin{array}{l}\text { Genipa americana } \\
\text { fruit extract, } \\
\text { xanthan gum, citric } \\
\text { acid, Lavandula } \\
\text { angustifolia herb o } \\
\text { il, potassium } \\
\text { sorbate }\end{array}$ & Dermatologically tested, vegan. \\
\hline JT-4 & & Powder & - & $\begin{array}{l}\text { Genipa americana, } \\
\text { sugar, xanthan } \\
\text { gum, citric acid }\end{array}$ & $\begin{array}{l}\text { Safe and non-toxic, not for use by children } 12 \text { years and } \\
\text { under, adult supervision advised, non-permanent, } 100 \% \\
\text { natural. }\end{array}$ \\
\hline JT-5 & & Paste & - & $\begin{array}{l}\text { Water, glycerine, } \\
\text { ethylhexylgycerol, } \\
\text { genipa juice, } \\
\text { hazelnut extract, } \\
\text { pure green plant } \\
\text { extract }\end{array}$ & Function, how to use and tips. Duration: 2 weeks. \\
\hline JT-6 & & Paste & - & $\begin{array}{c}\text { Inorganic plant } \\
\text { toner }(28 \%), \\
\text { natural emulsifier } \\
\text { (medical propylene } \\
\text { glycol, } 15 \%), \\
\text { gelatin water }(8 \%), \\
\text { thickener }(12 \%), \\
\text { medical distilled } \\
\text { water }(45 \%)\end{array}$ & $\begin{array}{l}\text { Magic tattoo pigment, color enhancer. Safe and natural, } \\
\text { without PPD or other toxic chemicals. Duration: } 2 \text { weeks. }\end{array}$ \\
\hline HPT & & $\begin{array}{l}\text { Liquid- } \\
\text { paste }\end{array}$ & - & None & $\begin{array}{l}\text { Herbaceous plant tattoo fluid. Vegetable dye, skin retention } \\
\text { time varies between individuals because skin metabolism is } \\
\text { slightly different. }\end{array}$ \\
\hline
\end{tabular}




\subsection{Sample Preparation}

The concept of minimal sample preparation seems increasingly attractive, since this step is often laborious and time-consuming and is the part of the analytical process most susceptible to errors that influence the quality of the results obtained. This idea puts pressure on the development of simpler and more efficient methods. The primary goal is to keep the manipulation of the sample as minimal as possible, close to the natural state of use. Therefore, following the desired trend towards simplification and standardization of the analytical method, a simple dilution and subsequent ultrasonic agitation are applied to ensure the complete solubility of the samples.

For each sample, $0.02-0.03 \mathrm{~g}$ of raw material and $7.5 \mathrm{~g}$ of methanol were exactly weighted into a $10 \mathrm{~mL}$ glass vial. Then, they were shaken in a Raypa ${ }^{\circledR}$ model UCI 150 ultrasonic bath (Barcelona, Spain) for $5 \mathrm{~min}$ at $35 \mathrm{kHz}$ of ultrasound frequency. Sample solutions were stored in glass vials at $-20^{\circ} \mathrm{C}$ until chromatographic analysis. Then, the solutions were filtered through a $0.22 \mu \mathrm{m}$ polytetrafluoroethylene (PTFE) syringe filter for its subsequent direct injection.

\subsection{Ultra-High-Performance Liquid Chromatography Quadrupole Time-of-Flight Mass Spectrometry (UHPLC-QOF-MS)}

Targeted and untargeted analyses of the samples were carried out in an Elute UHPLC 1300 coupled to a quadrupole time-of-flight mass spectrometry (QTOF) Compact Instrument (Bruker Daltonics, Bremen, Germany). Separation was carried out on an Intensity Solo HPLC column C18 (100 mm $\times 2.1 \mathrm{~mm}, 2.0 \mu \mathrm{m}$; Bruker Daltonics) which was kept at a constant temperature of $40{ }^{\circ} \mathrm{C}$. The mobile phase consists of $0.1 \%$ formic acid in both water (A) and methanol (B) and the flow rate was $0.25 \mathrm{~mL} \cdot \mathrm{min}^{-1}$. The adopted elution gradient starts at $95 \%$ A for $0.4 \mathrm{~min}$, then goes from $5 \% \mathrm{~B}$ to $35 \%$ in $0.1 \mathrm{~min}$ and to $100 \% \mathrm{~B}$ in $7 \mathrm{~min}$, and is held for $5 \mathrm{~min}$. Thus, it is returned to the initial conditions to re-equilibrate the column for the next injection reaching the $15 \mathrm{~min}$ of total run time. The injection was performed in a Microliter Pickup mode with $2 \mu \mathrm{L}$ of the samples, and each sample was injected in triplicate.

The QTOF-MS system was equipped with an electrospray ionization interface (ESI) operating with the following settings: endplate off-set of $500 \mathrm{~V}$, nebulizer pressure of 2 bar $\left(\mathrm{N}_{2}\right)$, drying gas of $8 \mathrm{~L} \cdot \mathrm{min}^{-1}$, drying temperature of $220^{\circ} \mathrm{C}$, and capillary voltage of $4000 \mathrm{~V}$ or $4500 \mathrm{~V}$ in negative and positive mode, respectively. In targeted analysis, the mass spectrometer was operated in negative mode, detecting mainly pseudo-molecular ions $[\mathrm{M}-\mathrm{H}]^{-}$. The MS method used was a broadband collision-induced dissociation (bbCID) approach, which allows the exhaustive recording of all detectable precursor and product ions, independently of precursor intensity. In untargeted analysis, electrospray ionization acquisition was performed with the Auto MS/MS method both in negative and positive modes, detecting mainly pseudo-molecular ions $[\mathrm{M}-\mathrm{H}]^{-}$and $[\mathrm{M}+\mathrm{H}]^{+}$, respectively. A QTOF external calibration was daily performed and a segment $(0.10-0.30 \mathrm{~min})$ in every chromatogram was used for internal calibration, using calibrant injection at the beginning of each run. The calibration mixture consisted of $10 \mathrm{mM}$ sodium formate in a mixture of $\mathrm{H}_{2} \mathrm{O}$ /isopropanol (1:1). The voltage ramp applied was from 10 to $105 \mathrm{eV}$, with a spectra rate of $8 \mathrm{~Hz}$ recording a scan range from 20 to $1000 \mathrm{~m} / \mathrm{z}$ (mass/charge), with a total cycle time range equal to $1 \mathrm{~s}$. The software package detailed below was used (Bruker Daltonics). All acquisitions were obtained using the Compass HyStar software, quantification was performed using the TASQ Version 2.1 (Build 201.2.4019) software and non-targeted searching with MetaboScape Compass Version 4.0.4 (Build 19) software. In TASQ, mass tolerance (mass window width) was $4 \mathrm{mDa}$, mSigma narrow window was \pm 10 , signal-to-noise $(\mathrm{S} / \mathrm{N})$ threshold of 0.1 , smoothing activated, minimum area threshold of 1500 and minimum intensity threshold of 200. The relative tolerance of the retention time (RT) window was set lower than $\pm 0.25 \mathrm{~min}$. In MetaboScape, algorithms based on intensity, mass error and isotopic profile were applied to process the list of compounds acquired. The identification was performed according to the exact mass accuracy and in combination with the calcula- 
tion of mSigma values. This factor provides a numerical comparison between theoretical and measured isotopic patterns based on the signal intensity deviations. The tool called SmartFormula was also used, which provides possible molecular structures of the acquired analytes by means of their mass accuracy, isotopic patterns, and MS/MS fragment information. Other tools such as MetFrag and CompoundCrawler were also employed, which perform in silico fragmentation of compounds chosen as possible structure candidates or searches in the main online databases of chemical compounds (Analyte DB, ChEBI, ChemSpider and PubChem), respectively $[17,18]$.

\section{Results and Discussion}

\subsection{Chromatographic Analysis}

The chromatographic and determination conditions were optimized to obtain the highest separation and resolution efficiency for unequivocal identification of the three target active compounds used in natural pigments-based tattoos and dyes. For UHPLCESI-QTOF analysis, RTs were 3.06, 3.50 and $4.26 \mathrm{~min}$, for geniposide, genipin and lawsone, respectively. Figure 1 shows the selected mass transitions of the targeted compounds, with the molecular ion and the fragmented ions structure based on molecular weight and the most likely fragmentation paths.
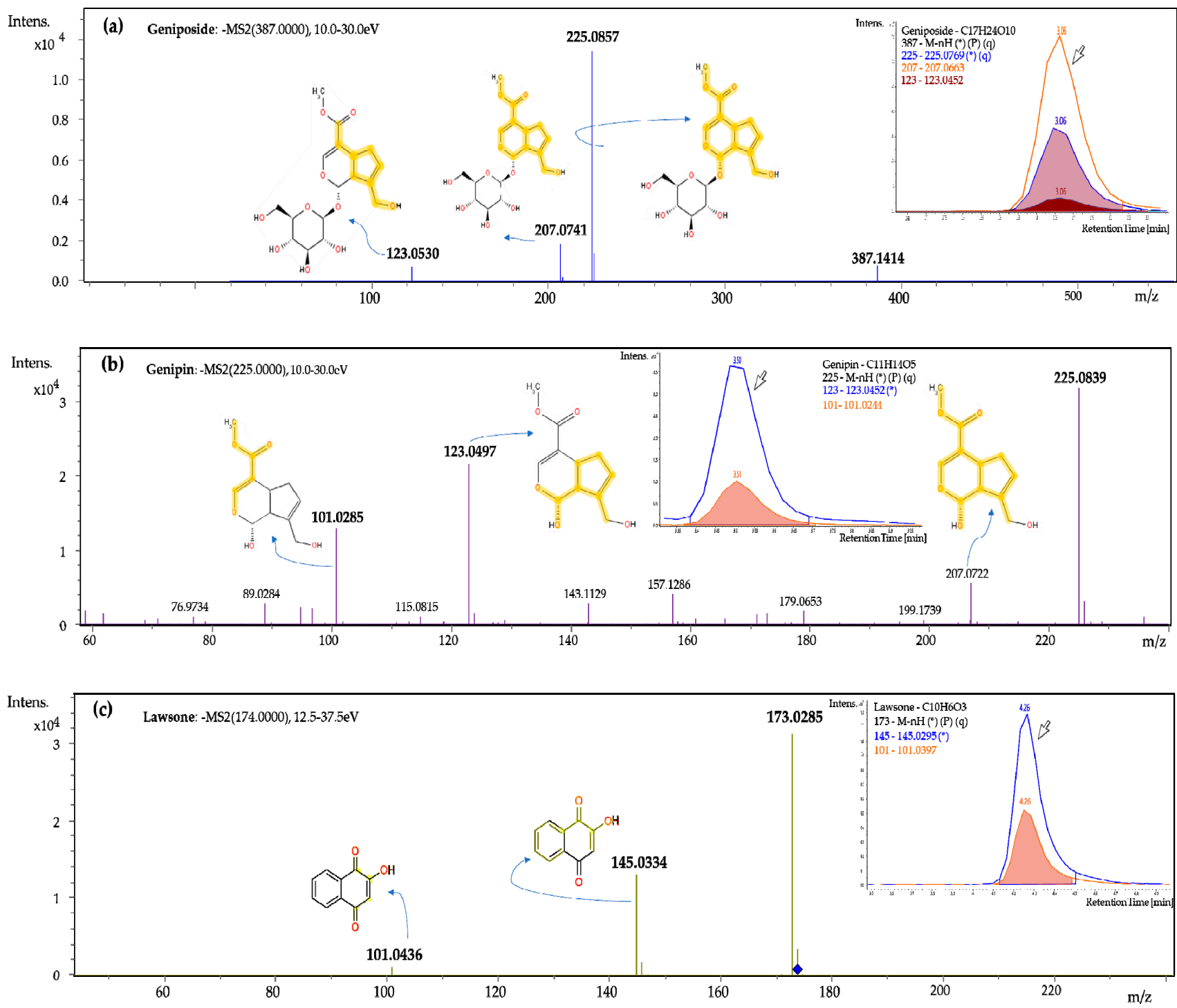

Figure 1. Chromatographic peak and mass spectra of the targeted compounds: (a) Geniposide, (b) Genipin, (c) Lawsone. 
The method was validated in terms of linearity and precision. Limits of detection (LODs) and quantification (LOQs) were also calculated. The results are depicted in Table 2. Calibration curves were obtained covering a concentration range of 0.1 to $2.5 \mu \mathrm{g} \cdot \mathrm{mL}^{-1}$ with standards (genipin and geniposide) prepared in methanol and with seven concentration levels and three replicates at each level. For lawsone, they were obtained in a range of 0.25 to $2.5 \mu \mathrm{g} \cdot \mathrm{mL}^{-1}$, with six concentration levels. The method exhibited a direct proportional relationship between the amount of each analyte and its chromatographic response, with coefficients of determination $\left(\mathrm{R}^{2}\right)$ higher than 0.990 in all cases. The instrumental method precision was evaluated $(n=3)$ for all the calibration concentration levels showing mean relative standard deviation (RSD) values lower than 5\%. Mean RSD values are shown in Table 2. The LODs and LOQs were calculated as the compound concentration giving a signal-to-noise ratio of three $(S / N=3)$ and ten $(S / N=10)$, respectively.

Table 2. UHPLC-QTOF performance. Linearity, precision, LODs and LOQs.

\begin{tabular}{ccccc}
\hline Compound & Linearity & $\begin{array}{c}\text { Mean Precision } \\
\text { RSD }(\mathbf{\%})\end{array}$ & $\begin{array}{c}\text { LODs } \\
\left(\mu \mathbf{g} \cdot \mathbf{m L} \mathbf{L}^{-1}\right)\end{array}$ & $\begin{array}{c}\text { LOQs } \\
\left(\boldsymbol{\mu} \mathbf{g} \cdot \mathbf{m L} \mathbf{m}^{-1}\right)\end{array}$ \\
\hline Genipin & 0.9925 & 4.7 & 0.06 & 0.2 \\
Geniposide & 0.9938 & 3.9 & 0.03 & 0.1 \\
Lawsone & 0.9909 & 4.2 & 0.02 & 0.06 \\
\hline
\end{tabular}

\subsection{Application to Real Samples}

Samples were analyzed using the previously described methodology. Henna-based products presented a wide range of tonalities. The analyses showed the presence of only some target analytes (Table 3a). Lawsone was only found in 9 of the 27 henna samples. Two of these nine are for temporary tattooing, four are for hair dyeing only and the remaining three have both purposes. Regarding the tattoo samples, the two in which the active ingredient was detected are brown, the truest and most typical color for this type of sample. Sample HT-11 is the most notable due to its high lawsone concentration. In the remaining colored hennas, lawsone was not detected. The absences of the active principle in other henna samples have already been reported $[3,4]$. However, the fraction of samples with lawsone in such studies was around $70-80 \%$, whereas we found only half of that percentage in the henna samples, reaching $33 \%$ of the total. This percentage increased when considering hennas intended for hair dyeing since hennas for temporary tattooing (HT) containing lawsone only represent $7.4 \%$, while those for hair-dyeing (HD) reached $14.8 \%$, and those for both purposes (HTD), 11\%. In fact, only 2 of 17 HT samples contained lawsone, while half of HD samples contained it. The three hennas with both purposes (HTD) stand out as they all contain lawsone. It is important to note that the samples reported in the literature were black, brown, or red, but in this study, samples of less typical colors such as pink, green, or blue, which were far from the initial idea of natural henna, were also considered.

Table 3. Analysis of targeted compound in samples. (a) Henna samples. (b) Jagua samples.

\begin{tabular}{|c|c|c|c|c|c|c|c|}
\hline \multirow{2}{*}{$\frac{\text { (a) }}{\text { Sample Code }}$} & \multicolumn{2}{|c|}{ Lawsone } & \multirow{2}{*}{$\begin{array}{c}\text { (b) } \\
\text { Sample Code }\end{array}$} & \multicolumn{2}{|c|}{ Genipin } & \multicolumn{2}{|c|}{ Geniposide } \\
\hline & $\left(\mu \mathrm{g} \cdot \mathrm{mL}^{-1}\right)$ & $\left(\mu g \cdot g^{-1}\right)$ & & $\left(\mu \mathrm{g} \cdot \mathrm{mL}^{-1}\right)$ & $\left(\mu g \cdot g^{-1}\right)$ & $\left(\mu \mathrm{g} \cdot \mathrm{mL}^{-1}\right)$ & $\left(\mu g \cdot g^{-1}\right)$ \\
\hline HT-11 ${ }^{c}$ & 20.5 & 7322.3 & JT-1 & 4.9 & 1681.5 & 3.6 & 1218.3 \\
\hline HTD-1 & 1.9 & 831.5 & JT-2 & 5.5 & 1936.9 & 0.2 & 70.4 \\
\hline HT-16 & 0.4 & 134.6 & JT-3 & 0.05 & 15.9 & 0.6 & 197.3 \\
\hline HTD-2 & 1.4 & 600.5 & JT-4 & 15.8 & 5579.6 & 18.7 & 6586.0 \\
\hline HTD-3 & 0.6 & 253.9 & JT-5 & 22.9 & 7310.7 & 1.9 & 607.9 \\
\hline HD-1 & 0.9 & 330.9 & JT-6 & 20.5 & 5887.3 & 0.6 & 158.0 \\
\hline HD-2 & 0.6 & 225.9 & HPT & - & - & - & - \\
\hline HD-5 & 1.5 & 587.7 & & & & & \\
\hline HD-7 & 1.6 & 543.8 & & & & & \\
\hline
\end{tabular}


The analyses yielded better results for jagua products in terms of authenticity. The average results are summarized in Table 3b. Genipin was found in all six samples considered, although with a broad concentration range, patent in the last three (JT-4 to JT-6), much smaller in JT-1 and JT-2, and with a presence in sample JT-3. Geniposide was also identified in all jagua preparations, with the highest concentration found in JT-4, the solid sample. It is shown that the high-resolution methodology now applied improves the LODs and allows the geniposide to be detected in all the samples included, whereas in the previous investigation with HPLC-DAD it was only possible in $50 \%$ of the samples studied [13]. Thus far, among the few papers reported about these two analytes in natural tattoo samples, only one mentions the detection of genipin. In any case, neither previous analytical approaches for the simultaneous quantification of these target compounds nor a high-resolution MS technique have been used. Comparing both compounds, the concentrations of the main active principle, genipin, are higher than those of geniposide in all samples except JT-4. Finally, as regards the sample considered as herbaceous plant tattoo (HPT), none of the mentioned targeted compounds was detected. This initially suggests that its origin is not based on jagua or henna extracts.

In summary, the proposed analytical method allows the suitable identification and determination of the active compounds in the natural pigments considered, improving the previous methodology concerning the specific analysis of geniposide in jagua samples.

\subsection{Identification of Untargeted Analytes by UHPLC-QTOF}

One of the most crucial challenges in metabolomics applications is the extreme dynamic range of analyte mixture abundances in complex natural samples. The compact QTOF is the tool of choice for analyzing batches of such highly complex samples, considering that it combines sensitivity, mass accuracy, MS/MS performance and robustness with sophisticated software for the evaluation of the data sets. Data processing and analysis are important and critical parts of this protocol. This part of the study explores the deep and effective characterization of potential new unidentified compounds in natural tattoo and dye samples. For the identification of the largest number of compounds, it is necessary to perform a highly sensitive analysis. For this reason, a high-resolution Auto MS/ MS acquisition was performed. One advantage is that no manual precursor selection is required, resulting in a shorter time compared to other acquisition methods. It combines MS scan cycles with programmed MS/MS scans, allowing both types of data collection in a single analysis [19]. Compounds were identified in samples with an implemented software postprocessing routine using different strategies, summarised in Figure 2 (Tables 4 and 5).

MetaboScape software can be used to perform data deconvolution, peak-picking and alignment to generate a list of mass features (called Bucket Table). After setting up a project and select data files to analyze, files may be grouped according to type. In this case, in two groups for jaguas: sample type (powder or paste), color (black or colorless) and in four for hennas: sample type (powder or paste), claim (tattoo, hair dye or both), seller (regarding sets) and color (with the different options detailed in Table 1). Including tandem data (MS/MS) will enable Metaboscape to perform spectral library matching and identification. Data processing parameters to create a bucket table (features list) are detailed in Figure 2. All detected features were displayed in the bucket table with their RT, measured $m / z$, molecular weight, detected ions and intensity in each sample. This table can then be used for statistical analysis or for compound identification using the other tools available in the software, detailed in the instrumentation section. The latter was the chosen option, as the primary objective is the in-depth characterization of the chemical composition of the samples, rather than the exploration of their statistical clustering. Six Bucket Tables were created: two for jagua in positive and negative mode, respectively, and the same for henna and HPT samples. Some publications use an algorithm based on the tolerance limits setting values of 5 ppm mass accuracy and $50 \mathrm{mSigma}$, respectively [20]. However, in our research, we have considered establishing values of $50 \mathrm{mSigma}$ and $5 \mathrm{mDa}$ as acceptable maxima in these deviations, following the instrumental specifications. 
Initially, the buckets obtained in the groups were compared to search for specific metabolites showing a higher intensity in one or the other group. From the exact mass obtained in these buckets, a molecular formula was chosen using SmartFormula with mSigma and mass accuracy values lower than 50 and $5 \mathrm{mDa}$, respectively. The molecular formula was then used for search in the online databases through CompoundCrawler tool, leading to manual putative structure identification. In order to help further identification, the MetFrag utility was also used to perform in silico fragmentation. Table 4 summarizes the RT, molecular formula, exact mass, deviations from exact mass or isotopic profile, ionization mode, and a proposed name for some examples of compounds. Among them, plant metabolites can be found and the presence of spiroxamine stands out as an active ingredient of certain fungicides. In addition, other compounds identified are common ingredients in cosmetic products, such as salicylic acid as a preservative, anti-seborrheic or conditioning agent for skin and hair (source: Cosmetic Ingredient Database, CosIng [21]).

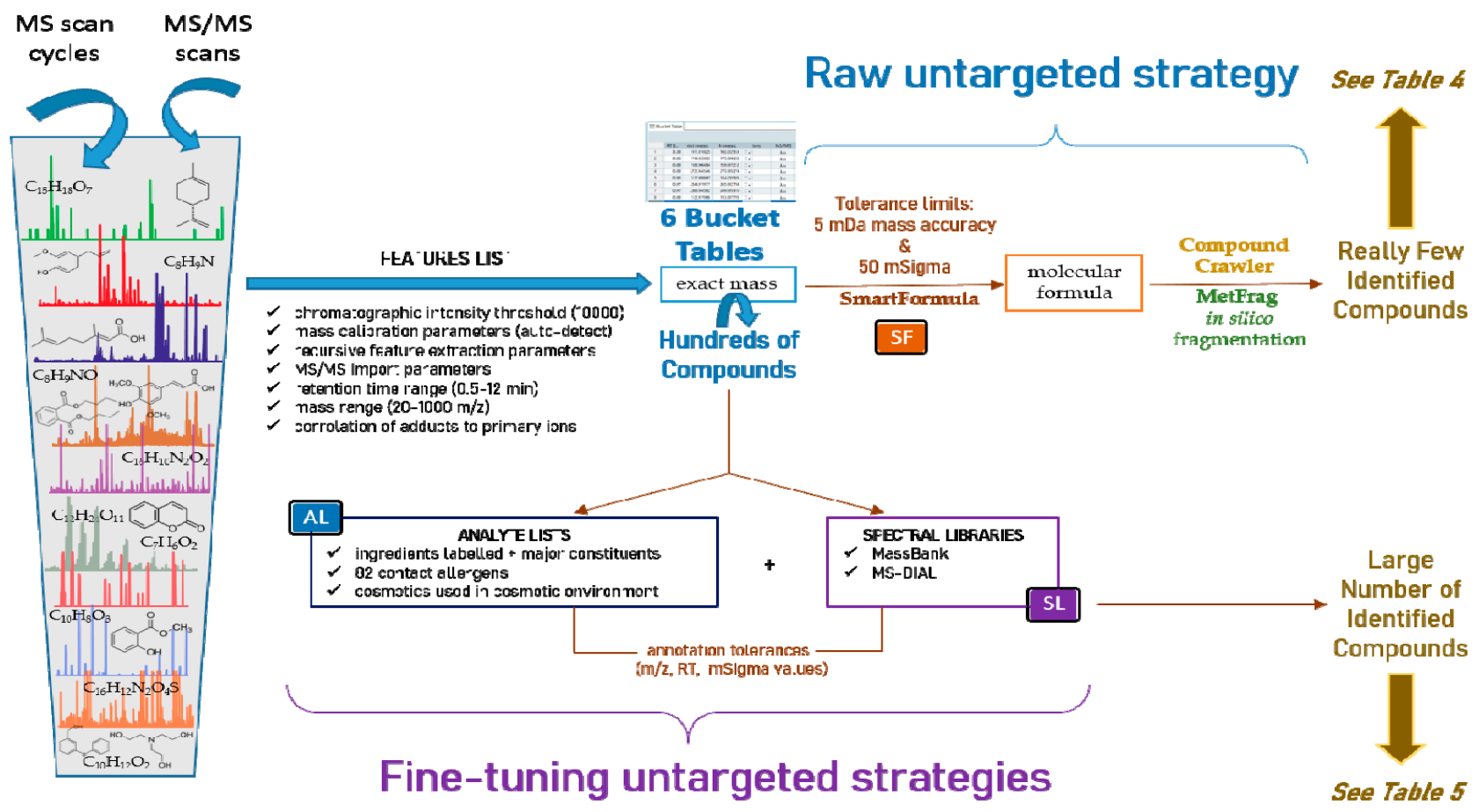

Figure 2. Scheme of post-processing untargeted routine combining raw and fine-tuning strategies.

Table 4. Examples of proposed compounds putatively identified applying the raw untargeted strategy.

\begin{tabular}{|c|c|c|c|c|c|c|}
\hline $\begin{array}{c}\mathrm{RT} \\
(\mathrm{min})\end{array}$ & $\begin{array}{l}\text { Accurate } \\
\text { Mass }\end{array}$ & $\begin{array}{l}\text { Molecular } \\
\text { Formula } \\
\text { (Error mDa) }\end{array}$ & mSigma & $\begin{array}{l}\text { Ionization } \\
\text { Mode }\end{array}$ & Proposed Structure & $\begin{array}{l}\text { Mostly Found in } \\
\text { Samples }\end{array}$ \\
\hline 1.10 & 325.12512 & $\mathrm{C}_{16} \mathrm{H}_{20} \mathrm{O}_{7}(3.06)$ & 32.9 & + & 11-Hydroxymonocerin & JT-2 \\
\hline 1.53 & 195.03460 & $\mathrm{C}_{9} \mathrm{H}_{8} \mathrm{O}_{5}(4.63)$ & 13.7 & - & 3,4-Dihydroxyphenylpyruvic acid & JT-4, JT-1, JT-2 \\
\hline 1.96 & 191.00304 & $\mathrm{C}_{9} \mathrm{H}_{4} \mathrm{O}_{5}(4.25)$ & 14.5 & - & Trimellitic anhydride & JT- 4 \\
\hline 2.70 & 219.05053 & $\mathrm{C}_{8} \mathrm{H}_{12} \mathrm{O}_{7}(0.49)$ & 6.5 & - & (-)-Threo-isodihomocitric acid & $\mathrm{HPT}$ \\
\hline 4.09 & 259.05764 & $\mathrm{C}_{12} \mathrm{H}_{12} \mathrm{O}_{5}(0.08)$ & 16.6 & + & 5,7,8-Trimethoxycoumarin & $\begin{array}{l}\text { HTD-1, HD-5, } \\
\text { HTD-2, HTD-3 }\end{array}$ \\
\hline 4.30 & 182.98801 & $\mathrm{C}_{7} \mathrm{H}_{4} \mathrm{O}_{6}(3.50)$ & 0.8 & - & Chelidonic acid & HT-14, HT-13, HT-12 \\
\hline 4.38 & 137.01963 & $\mathrm{C}_{7} \mathrm{H}_{6} \mathrm{O}_{3}(4.70)$ & 8.5 & - & Salicylic acid & HT- 4 \\
\hline 7.61 & 280.26289 & $\mathrm{C}_{18} \mathrm{H}_{35} \mathrm{NO}_{2}(0.60)$ & 19.9 & + & Spiroxamine & JT-1, JT-4, JT-5 \\
\hline 9.03 & 381.29836 & $\mathrm{C}_{21} \mathrm{H}_{42} \mathrm{O}_{4}(0.80)$ & 7.3 & + & Glyceryl monostearate & HТ-14, НТ-13, НТ-16 \\
\hline
\end{tabular}




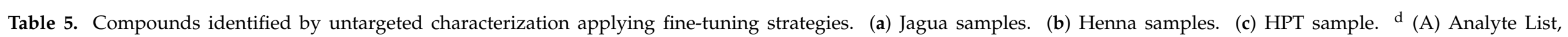
(B) Spectral Library.

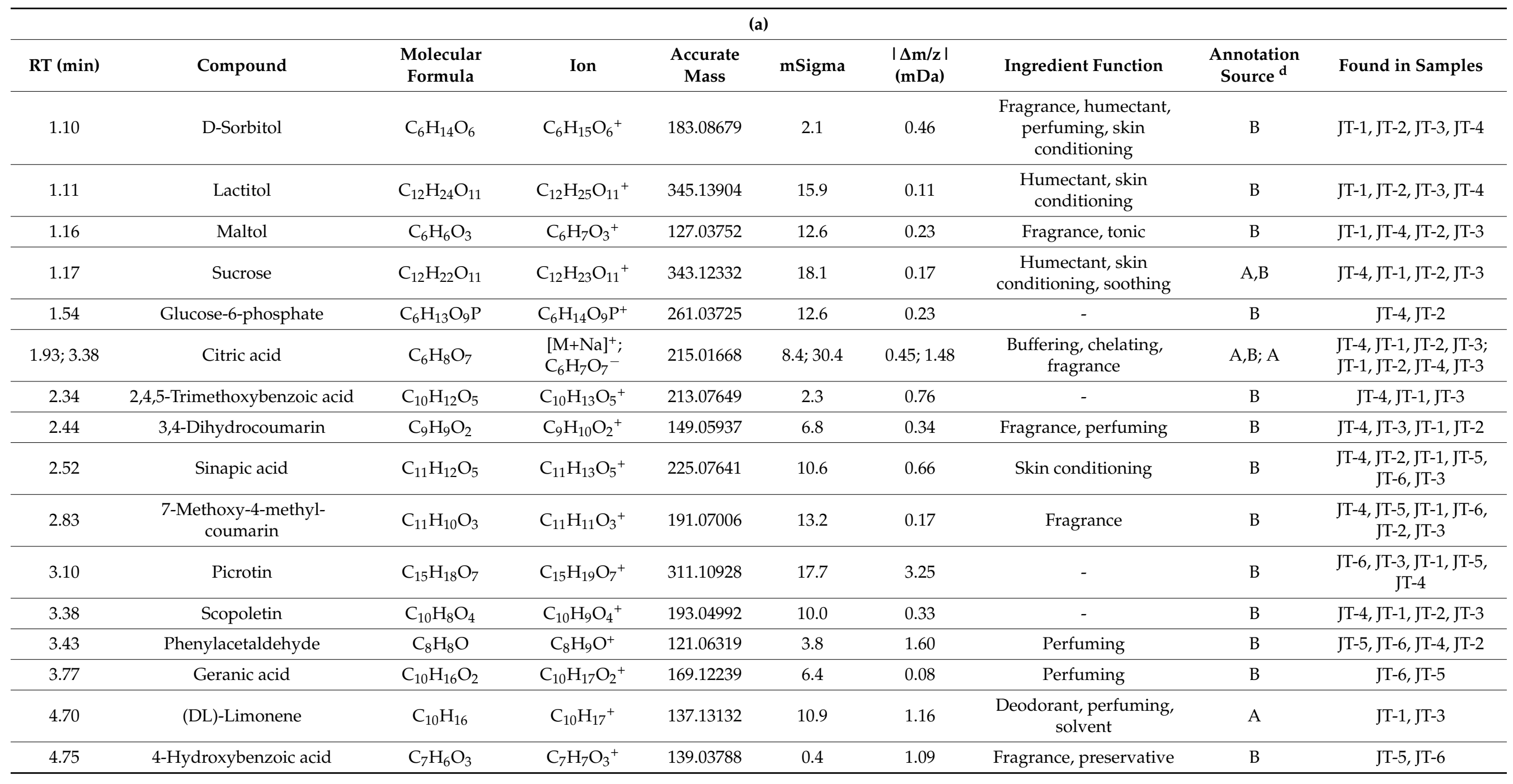


Table 5. Cont.

\begin{tabular}{|c|c|c|c|c|c|c|c|c|c|}
\hline \multicolumn{10}{|c|}{ (a) } \\
\hline RT (min) & Compound & $\begin{array}{l}\text { Molecular } \\
\text { Formula }\end{array}$ & Ion & $\begin{array}{l}\text { Accurate } \\
\text { Mass }\end{array}$ & mSigma & $\begin{array}{c}|\Delta \mathrm{m} / \mathrm{z}| \\
(\mathrm{mDa})\end{array}$ & Ingredient Function & $\begin{array}{l}\text { Annotation } \\
\text { Source }\end{array}$ & Found in Samples \\
\hline 4.83 & Benzaldehyde & $\mathrm{C}_{7} \mathrm{H}_{6} \mathrm{O}$ & $\mathrm{C}_{7} \mathrm{H}_{7} \mathrm{O}^{+}$ & 107.04719 & 5.1 & 1.96 & $\begin{array}{c}\text { Denaturant, fragrance, } \\
\text { perfuming }\end{array}$ & $\mathrm{A}, \mathrm{B}$ & JT-4, JT-5, JT-2 \\
\hline 5.17 & N-Butylbenzenesulfonamide & $\mathrm{C}_{10} \mathrm{H}_{15} \mathrm{NO}_{2} \mathrm{~S}$ & $\mathrm{C}_{10} \mathrm{H}_{16} \mathrm{NO}_{2} \mathrm{~S}^{+}$ & 214.09072 & 7.8 & 1.17 & - & B & $\begin{array}{c}\text { JT-3, JT-1, JT-2, JT-4, } \\
\text { JT-5, JT-6 }\end{array}$ \\
\hline 6.00 & Eudesmin & $\mathrm{C}_{22} \mathrm{H}_{26} \mathrm{O}_{6}$ & $\mathrm{C}_{22} \mathrm{H}_{27} \mathrm{O}_{6}{ }^{+}$ & 387.17996 & 10.9 & 0.71 & - & B & $\begin{array}{c}\text { JT-5, JT-6, JT-2, JT-3, } \\
\text { JT-4, JT-1 }\end{array}$ \\
\hline 7.07 & Auraptene & $\mathrm{C}_{19} \mathrm{H}_{22} \mathrm{O}_{3}$ & $\mathrm{C}_{19} \mathrm{H}_{23} \mathrm{O}_{3}{ }^{+}$ & 299.16123 & 20.8 & 3.04 & - & B & $\begin{array}{c}\text { JT-1, JT-2, JT-3, JT-6, } \\
\text { JT-4, JT-5 }\end{array}$ \\
\hline 7.19 & Cocamidopropyl betaine & $\mathrm{C}_{19} \mathrm{H}_{38} \mathrm{~N}_{2} \mathrm{O}_{3}$ & $\mathrm{C}_{19} \mathrm{H}_{39} \mathrm{~N}_{2} \mathrm{O}_{3}{ }^{+}$ & 343.29507 & 12.4 & 0.52 & $\begin{array}{l}\text { Antistatic, cleansing, hair } \\
\text { conditioning, skin } \\
\text { conditioning, } \\
\text { surfactant-foam boosting, } \\
\text { viscosity controlling }\end{array}$ & B & $\begin{array}{c}\text { JT-3, JT-4, JT-1, JT-2, } \\
\text { JT-5, JT-6 }\end{array}$ \\
\hline 7.37 & Phthalic anhydride & $\mathrm{C}_{8} \mathrm{H}_{4} \mathrm{O}_{3}$ & $\mathrm{C}_{8} \mathrm{H}_{5} \mathrm{O}_{3}{ }^{+}$ & 149.02269 & 3.3 & 0.63 & - & B & $\begin{array}{c}\text { JT-1, JT-2, JT-3, JT-4, } \\
\text { JT-5, JT-6 }\end{array}$ \\
\hline 8.57 & Acetanilide & $\mathrm{C}_{8} \mathrm{H}_{9} \mathrm{NO}$ & $\mathrm{C}_{8} \mathrm{H}_{10} \mathrm{NO}^{+}$ & 136.07487 & 3.4 & 0.82 & Fragrance, perfuming & B & $\begin{array}{c}\text { JT-3, JT-1, JT-2, JT-4, } \\
\text { JT-5 }\end{array}$ \\
\hline 8.85 & Triethanolamine & $\mathrm{C}_{6} \mathrm{H}_{15} \mathrm{NO}_{3}$ & $\mathrm{C}_{6} \mathrm{H}_{16} \mathrm{NO}_{3}^{+}$ & 150.11214 & 13.3 & 0.33 & $\begin{array}{l}\text { Buffering, fragrance, } \\
\text { surfactant-cleansing, } \\
\text { surfactant-emulsifying }\end{array}$ & B & $\begin{array}{c}\text { JT-3, JT-6, JT-1, JT-2, } \\
\text { JT-4, JT-5 }\end{array}$ \\
\hline 8.96 & $\begin{array}{l}\text { 2-Acetoxy-4- } \\
\text { pentadecylbenzoic } \\
\text { acid }\end{array}$ & $\mathrm{C}_{24} \mathrm{H}_{38} \mathrm{O}_{4}$ & $\mathrm{C}_{24} \mathrm{H}_{39} \mathrm{O}_{4}^{+}$ & 391.28321 & 10.2 & 0.73 & - & B & $\begin{array}{c}\text { JT-3, JT-1, JT-2, JT-4, } \\
\text { JT-6, JT-5 }\end{array}$ \\
\hline 8.97 & Dibutyl phthalate & $\mathrm{C}_{16} \mathrm{H}_{22} \mathrm{O}_{4}$ & $\mathrm{C}_{16} \mathrm{H}_{23} \mathrm{O}_{4}{ }^{+}$ & 279.15887 & 5.0 & 0.10 & $\begin{array}{l}\text { Fragrance, perfuming, } \\
\text { plasticiser, solvent }\end{array}$ & B & $\begin{array}{c}\text { JT-1, JT-2, JT-6, JT-3, } \\
\text { JT-4, JT-5 }\end{array}$ \\
\hline 1.09 & D-Sorbitol & $\mathrm{C}_{6} \mathrm{H}_{14} \mathrm{O}_{6}$ & $\mathrm{C}_{6} \mathrm{H}_{15} \mathrm{O}_{6}^{+}$ & 183.08686 & 1.7 & 0.52 & $\begin{array}{l}\text { Fragrance, humectant, } \\
\text { perfuming, skin } \\
\text { conditioning }\end{array}$ & B & $\begin{array}{l}\text { All HTD and HD, } \\
\text { HT-16, HT-11 }\end{array}$ \\
\hline
\end{tabular}


Table 5. Cont.

\begin{tabular}{|c|c|c|c|c|c|c|c|c|c|}
\hline \multicolumn{10}{|c|}{ (b) } \\
\hline RT (min) & Compound & $\begin{array}{l}\text { Molecular } \\
\text { Formula }\end{array}$ & Ion & $\begin{array}{l}\text { Accurate } \\
\text { Mass }\end{array}$ & mSigma & $\begin{array}{l}|\Delta \mathrm{m} / \mathrm{z}| \\
(\mathrm{mDa})\end{array}$ & Ingredient Function & $\begin{array}{l}\text { Annotation } \\
\text { Source } \\
d\end{array}$ & Found in Samples \\
\hline 1.20 & Natural Red 4(CI 75470) & $\mathrm{C}_{22} \mathrm{H}_{20} \mathrm{O}_{13}$ & $\mathrm{C}_{22} \mathrm{H}_{19} \mathrm{O}_{13}-$ & 491.08009 & 9.8 & 2.96 & Colorant, fragance & $\mathrm{A}$ & $\begin{array}{c}\text { HT-3, HT-2, HTD-3, } \\
\text { HT-6, HT-1, HT-4, } \\
\text { HT-7, HTD-1, HTD-2, } \\
\text { HT-16 }\end{array}$ \\
\hline 1.94 & 4-Aminophenol & $\mathrm{C}_{6} \mathrm{H}_{7} \mathrm{NO}$ & $\mathrm{C}_{6} \mathrm{H}_{8} \mathrm{NO}^{+}$ & 110.05750 & 5.8 & 2.52 & Hair dyeing & $\mathrm{B}$ & HTD-3, HD-2, HD-3 \\
\hline 2.77 & Vanillic acid & $\mathrm{C}_{8} \mathrm{H}_{8} \mathrm{O}_{4}$ & $\mathrm{C}_{8} \mathrm{H}_{9} \mathrm{O}_{4}^{+}$ & 169.04958 & 3.4 & 0.06 & - & $\mathrm{B}$ & $\begin{array}{l}\text { All HTD and HD, } \\
\text { HT-13, HT-2, HT-7 }\end{array}$ \\
\hline 2.85 & Quinine & $\mathrm{C}_{20} \mathrm{H}_{24} \mathrm{~N}_{2} \mathrm{O}_{2}$ & $\mathrm{C}_{20} \mathrm{H}_{25} \mathrm{~N}_{2} \mathrm{O}_{2}^{+}$ & 325.19068 & 20.1 & 0.38 & $\begin{array}{l}\text { Denaturant, fragrance, } \\
\text { hair conditioning }\end{array}$ & $\mathrm{B}$ & HD-1 \\
\hline 3.06 & Syringic acid & $\mathrm{C}_{9} \mathrm{H}_{10} \mathrm{O}_{5}$ & $\mathrm{C}_{9} \mathrm{H}_{11} \mathrm{O}_{5}{ }^{+}$ & 199.06043 & 8.9 & 0.12 & Antioxidant & B & $\begin{array}{l}\text { HD-2, HD-1, HTD-3, } \\
\text { HD-3 }\end{array}$ \\
\hline 3.53 & alpha-Santonin & $\mathrm{C}_{15} \mathrm{H}_{18} \mathrm{O}_{3}$ & $\mathrm{C}_{15} \mathrm{H}_{19} \mathrm{O}_{3}{ }^{+}$ & 247.13066 & 18.7 & 2.21 & - & $\mathrm{B}$ & All HTD and HD \\
\hline 3.55 & Vitexin & $\mathrm{C}_{21} \mathrm{H}_{20} \mathrm{O}_{10}$ & $\mathrm{C}_{21} \mathrm{H}_{21} \mathrm{O}_{10}^{+}$ & 433.11296 & 1.5 & 0.28 & - & B & $\begin{array}{l}\text { HTD-1, HD-7, HD-5, } \\
\text { HTD-2, HTD-3, } \\
\text { HT-16, HD-4, HD-1 }\end{array}$ \\
\hline 3.70 & Quercetin & $\mathrm{C}_{15} \mathrm{H}_{10} \mathrm{O}_{7}$ & $\mathrm{C}_{15} \mathrm{H}_{11} \mathrm{O}_{7}^{+}$ & 303.05016 & 3.9 & 0.23 & $\begin{array}{l}\text { Antioxidant, skin } \\
\text { conditioning }\end{array}$ & A & All HD and HTD-1 \\
\hline 3.87 & Ellagic acid & $\mathrm{C}_{14} \mathrm{H}_{6} \mathrm{O}_{8}$ & $\mathrm{C}_{14} \mathrm{H}_{7} \mathrm{O}_{8}{ }^{+}$ & 303.01326 & 14.0 & 0.28 & Skin conditioning & B & $\begin{array}{l}\text { All HTD and HD (less } \\
\text { HD-3, HD-6), HT-16 }\end{array}$ \\
\hline 3.97 & Lawsonicin & $\mathrm{C}_{20} \mathrm{H}_{24} \mathrm{O}_{6}$ & {$[\mathrm{M}+\mathrm{Na}]^{+}$} & 383.14636 & 20.7 & 0.06 & - & A & $\begin{array}{l}\text { HT-11, HT-16, HD-1, } \\
\text { HD-7 }\end{array}$ \\
\hline
\end{tabular}


Table 5. Cont.

\begin{tabular}{|c|c|c|c|c|c|c|c|c|c|}
\hline \multicolumn{10}{|c|}{ (b) } \\
\hline RT (min) & Compound & $\begin{array}{l}\text { Molecular } \\
\text { Formula }\end{array}$ & Ion & $\begin{array}{l}\text { Accurate } \\
\text { Mass }\end{array}$ & mSigma & $\begin{array}{l}|\Delta \mathrm{m} / \mathrm{z}| \\
(\mathrm{mDa})\end{array}$ & Ingredient Function & $\begin{array}{l}\text { Annotation } \\
\text { Source } d\end{array}$ & Found in Samples \\
\hline 4.07 & Methyl salicylate & $\mathrm{C}_{8} \mathrm{H}_{8} \mathrm{O}_{3}$ & $\mathrm{C}_{8} \mathrm{H}_{9} \mathrm{O}_{3}{ }^{+}$ & 153.05422 & 6.7 & 0.43 & $\begin{array}{l}\text { Denaturant, oral care, } \\
\text { perfuming, soothing }\end{array}$ & $\mathrm{A}$ & HT-13, HT-14, HT-1 \\
\hline 4.19 & Salicylaldehyde & $\mathrm{C}_{7} \mathrm{H}_{6} \mathrm{O}_{2}$ & $\mathrm{C}_{7} \mathrm{H}_{7} \mathrm{O}_{2}{ }^{+}$ & 123.04385 & 4.0 & 0.20 & Perfuming & $\mathrm{A}, \mathrm{B}$ & All \\
\hline 4.25 & Hydroxycitronellal & $\mathrm{C}_{10} \mathrm{H}_{20} \mathrm{O}_{2}$ & {$[\mathrm{M}+\mathrm{Na}]^{+}$} & 195.13601 & 1.7 & 0.43 & Perfuming & $\mathrm{A}$ & $\begin{array}{l}\text { HT-16, HT-14, HT-13, } \\
\text { HT-15 }\end{array}$ \\
\hline 4.26 & $\begin{array}{c}\text { Hydroxyisohexyl 3- } \\
\text { cyclohexene carboxaldehyde } \\
\text { (HICC)/Lyral }{ }^{\circledR}\end{array}$ & $\mathrm{C}_{13} \mathrm{H}_{22} \mathrm{O}_{2}$ & $\mathrm{C}_{13} \mathrm{H}_{23} \mathrm{O}_{2}^{+}$ & 211.16982 & 11.9 & 0.59 & Fragrance, perfuming & $\mathrm{A}$ & $\begin{array}{l}\text { All HD and HTD, } \\
\text { HT-16 }\end{array}$ \\
\hline 4.39 & 7-Methoxycoumarin & $\mathrm{C}_{10} \mathrm{H}_{8} \mathrm{O}_{3}$ & {$[\mathrm{M}+\mathrm{Na}]^{+}$} & 199.03715 & 6.8 & 0.43 & Fragrance & B & HD-6 \\
\hline 4.77 & Tinnevellin glucoside & $\mathrm{C}_{20} \mathrm{H}_{24} \mathrm{O}_{9}$ & $\mathrm{C}_{20} \mathrm{H}_{25} \mathrm{O}_{9}^{+}$ & 431.13127 & 13.4 & 0.02 & - & $\mathrm{B}$ & HD-6 \\
\hline 4.85 & Luteolin & $\mathrm{C}_{15} \mathrm{H}_{10} \mathrm{O}_{6}$ & $\mathrm{C}_{15} \mathrm{H}_{11} \mathrm{O}_{6}^{+}$ & 287.05472 & 3.3 & 0.21 & Skin conditioning & B & $\begin{array}{l}\text { HT-16, HT-11, all } \\
\text { HTD and HD }\end{array}$ \\
\hline 4.89 & Hexyl cinnamal & $\mathrm{C}_{15} \mathrm{H}_{20} \mathrm{O}$ & $\mathrm{C}_{15} \mathrm{H}_{21} \mathrm{O}^{+}$ & 217.15919 & 8.6 & 0.61 & Perfuming & A & HD-6 \\
\hline 5.29 & Daidzein & $\mathrm{C}_{15} \mathrm{H}_{10} \mathrm{O}_{4}$ & $\mathrm{C}_{15} \mathrm{H}_{11} \mathrm{O}_{4}^{+}$ & 255.06527 & 6.0 & 0.08 & $\begin{array}{l}\text { Skin conditioning- } \\
\text { miscellaneous }\end{array}$ & B & HD-6 \\
\hline 5.46 & Eugenol & $\mathrm{C}_{10} \mathrm{H}_{12} \mathrm{O}_{2}$ & $\mathrm{C}_{10} \mathrm{H}_{13} \mathrm{O}_{2}^{+}$ & 165.09123 & 10.1 & 0.20 & $\begin{array}{l}\text { Denaturant, perfuming, } \\
\text { tonic }\end{array}$ & $\mathrm{A}, \mathrm{B}$ & All \\
\hline 5.86 & Glycitein & $\mathrm{C}_{16} \mathrm{H}_{12} \mathrm{O}_{5}$ & $\mathrm{C}_{16} \mathrm{H}_{13} \mathrm{O}_{5}^{+}$ & 285.07564 & 7.5 & 0.11 & $\begin{array}{l}\text { Antioxidant, skin } \\
\text { conditioning, skin } \\
\text { protecting }\end{array}$ & $\mathrm{B}$ & HD-6 \\
\hline 6.00 & Eudesmin & $\mathrm{C}_{22} \mathrm{H}_{26} \mathrm{O}_{6}$ & $\mathrm{C}_{22} \mathrm{H}_{27} \mathrm{O}_{6}^{+}$ & 387.18009 & 3.7 & 0.07 & - & $\mathrm{B}$ & All \\
\hline 6.21 & Bisdemethoxy-curcumin & $\mathrm{C}_{19} \mathrm{H}_{16} \mathrm{O}_{4}$ & $\mathrm{C}_{19} \mathrm{H}_{17} \mathrm{O}_{4}^{+}$ & 309.11250 & 4.3 & 0.37 & Antioxidant & B & HD-6 \\
\hline 6.21 & Acid Orange 7(CI 15510) & $\mathrm{C}_{16} \mathrm{H}_{12} \mathrm{~N}_{2} \mathrm{O}_{4} \mathrm{~S}$ & $\mathrm{C}_{16} \mathrm{H}_{13} \mathrm{~N}_{2} \mathrm{O}_{4} \mathrm{~S}^{+}$ & 329.05884 & 11.5 & 0.15 & Hair dyeing & B & $\begin{array}{l}\text { HT-10, HT-13, HT-15, } \\
\text { HT-1, HT-2, HT-12 }\end{array}$ \\
\hline 6.24 & Demethoxycurcumin & $\mathrm{C}_{20} \mathrm{H}_{18} \mathrm{O}_{5}$ & $\mathrm{C}_{20} \mathrm{H}_{19} \mathrm{O}_{5}{ }^{+}$ & 339.12249 & 5.1 & 0.21 & Antioxidant & A & HD-6 \\
\hline 6.32 & 3-Phenoxybenzylalcohol & $\mathrm{C}_{13} \mathrm{H}_{12} \mathrm{O}_{2}$ & $\mathrm{C}_{13} \mathrm{H}_{13} \mathrm{O}_{2}^{+}$ & 201.09201 & 8.1 & 1.00 & - & B & HD-6 \\
\hline
\end{tabular}


Table 5. Cont.

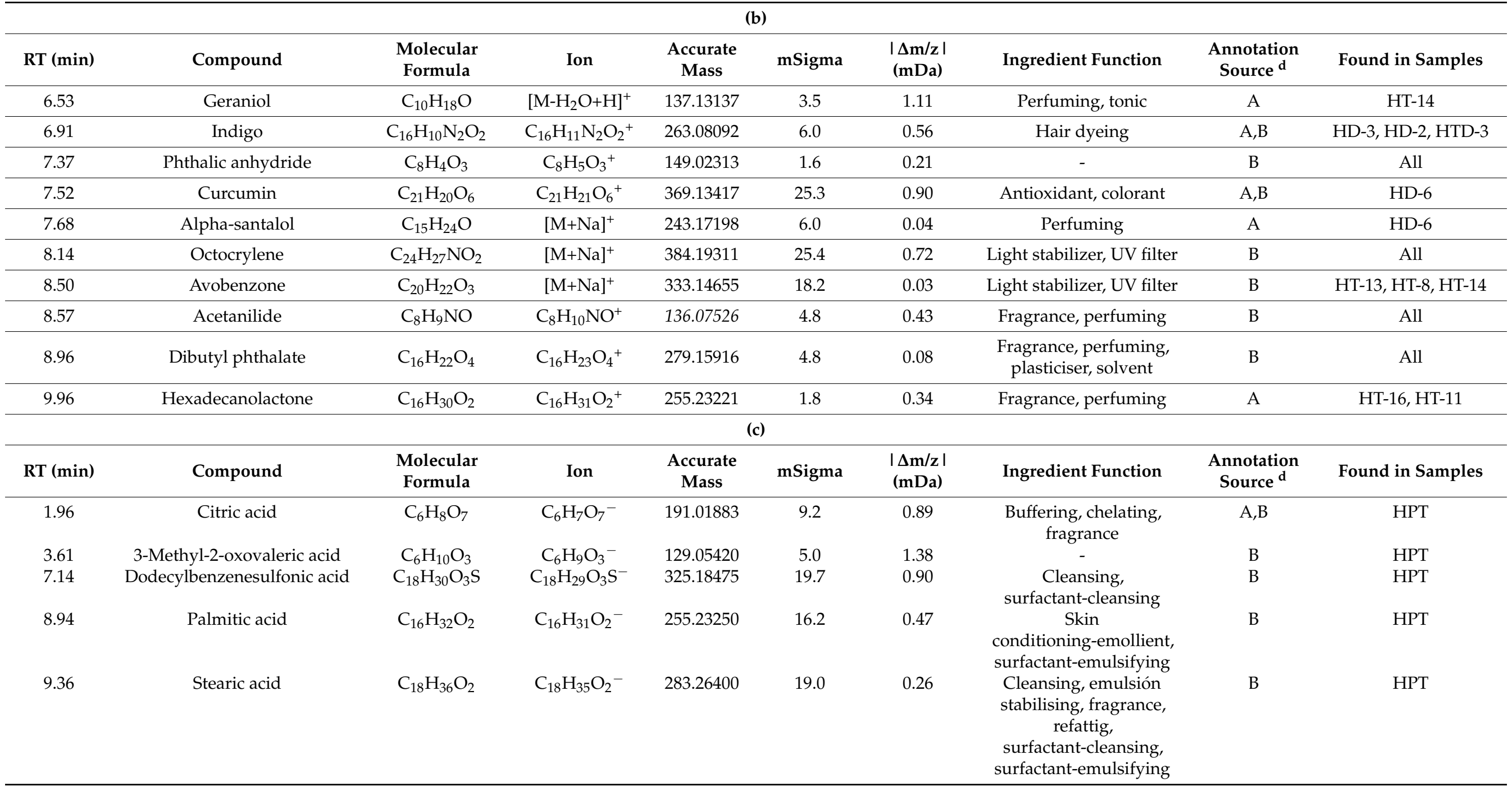


This is the first part of the non-targeted study, which only shows the identification of nine examples among the hundreds of compounds returned by the initial bucket tables. However, due to this high number of compounds, unequivocal identification is unfeasible without additional strategies as will be explained below. Here, it is also important to underline the difficulty of identifying compounds in this unique way, due to the lack of available literature. It is quite risky to assign a supposed name to a structure without any additional help other than the limiting parameters that are marked in the raw untargeted strategy. For this reason, other fine-tuning strategies were considered. Then, from the sample ingredients labeled, a list of compounds (called Analyte List, AL in MetaboScape) was created. In addition, a thorough bibliographic search was carried out to additionally include the major expected compounds of some labeled extracts in this list. This inspired the idea of creating another AL with the 82 contact allergens [22] that may be contained in natural extracts, as well as a third AL with colorants commonly used in the cosmetics environment [23]. The system generates the exact masses from the molecular formula of the chosen analytes. The compounds will be identified by the previous ALs implemented in the software, specifying annotation parameters such as tolerances for $m / z$, RT or mSigma values. Thus, the complex non-targeted process begins, where the compounds of interest have to be distinguishable from noise and interference signals. Then, the next step was to search from extensive public libraries (called Spectral Library, SL in MetaboScape). MassBank [24] and MS-DIAL [25] were used in both polarities, with data acquired at HRMS that include information about name, structure, exact mass, peaks and neutral losses of a great number of compounds.

Through the last two strategies of untargeted analysis (AL and SL), as shown in Table 5, a large number of interesting compounds, which had not been reported prior to this study, were identified in the analyzed samples. Table 5 lists the name, RT, molecular formula, ion, exact mass as well deviations from exact mass, and isotopic profile for each of the uncovered compounds. In addition, the last two columns include the cosmetic role of each ingredient [21], as well as its presence in the samples in order of intensity (only intensities over $10^{3}$ were considered).

A great variety of compounds were found in jaguas (Table 5a), such as carboxylic or aromatic acids, alcohols, a phthalate, plant compounds, predominantly terpenoids, coumarin derivatives and sugars. From the list of 26 compounds, many of them appear in most or all the samples.

For hennas, studies of plant phytochemical profiles, which are crucial for the establishment of adequate quality control protocols, are scarce. Although the active constituent of the leaf is lawsone, various other constituents have been isolated from the leaves and other parts of the plant such as stem bark, roots, flowers or seeds. These include gallic acid, sugars, tannins, xanthones, coumarins, flavonoids, naphthoquinones, terpenoids, aliphatic constituents and phenolic glycosides [26-28]. In this study, a wider variety of compounds were found for hennas (Table 5b), such as carboxylic acids, alcohols, the same phthalate as in jaguas, curcuminoids, flavonoids, colorants and coumarin derivatives, among others. Ten of the 39 compounds belong to the 82 contact allergens AL [22], while only two do in the case of jaguas. Regarding colorants, the detected Acid Orange 7 has been evaluated by the SCCS [29]. It is concluded that as a hair dye ingredient, up to a given final concentration under non-oxidative conditions, it is safe, but for other cosmetic products where the amount added is unknown, the safety of the dye cannot be evaluated. In this work, it has been found in samples that are initially sold for temporary tattoos and not as hair dye. Some of the compounds are specific for the tattoo-type hennas and others for hair dyeing hennas. In addition, other analytes were found only in a single sample, as is the case for HD-1 and repeatedly for HD-6.

On the other hand, those temporary tattoo hennas in which lawsone has been found, that is, real hennas, have certain characteristic compounds differing from the group of black hennas. A phytochemical study has reported this fact: the authentic sample of reddish-brown henna was completely different from black henna. Moreover, samples of 
real henna hair dye contain plant compounds and other chemicals that were not listed in the product information [30]. The purpose of adding other plants or natural or synthetic chemical substances may be to modify the hair color, improve penetration or fixation of the dye, enhance hair color, improve hair protection and effects that occur with numerous associated additives, from keratin to heavy metals. In the case of hair dye hennas, the different ingredients listed on each one are intended to explain the expected hair dye color. Thus, HD-1 is labeled to achieve a light brown hair color, HD-2 for dark brown, HD-3 for black, HD-4 for auburn, HD-5 for natural copper and HD-6 for deep blonde hair.

For the HPT sample (Table 5c), among the five compounds reported, carboxylic acids and saturated fatty acids were found.

Nowadays, temporary dyes are widely used, but they still lack the necessary controls. Concerns about the quality determination of imported raw materials for producers and about the safety of dyeing products is very high. Therefore, it is important to verify the condition, origin and identity of the raw material used, as well as the marketed final product. There are differences between products due to the origin of the raw material, the presence of other plants or the use of additives that can cause allergies. In the specific case of henna, products sold as henna contain other natural dyes [31] that give rise to another type of henna. In addition, these products may include essential oils or other solvents that can enhance and influence the staining of the skin or hair.

\section{Conclusions and Future Trends}

In this work, a method based on UHPLC-QTOF-MS has been proposed to simultaneously evaluate the presence of the active ingredients in plant-pigment-based tattoo and dye formulations. Furthermore, it includes a step further using metabolomics techniques for their characterization. It is worth mentioning that sample preparation is extremely conservative, being minimized. The method performance study showed that LC-QTOF was appropriate, allowing rapid quantification of the expected active ingredients of the samples. Only 9 out of 27 henna samples analyzed contained lawsone, clearly indicating that more than $50 \%$ of products sold as henna are fraudulent. For jaguas, genipin and geniposide were found in all samples, meaning that the six available samples were jagua-based, although with differences in the levels of active ingredients.

This is an example of how technology combining LC with high-resolution MS helps to determine the authenticity of species and to detect false labeling or even help to discover ingredients through untargeted analysis. A total of 70 unknown compounds were found in these types of samples, including alcohols, coumarin derivatives, terpenoids and flavonoids, among others. Analyte lists and spectral libraries have been able to supply the challenge of the most manual identification in the software, which could not be supported by the bibliography since it is practically non-existent. In summary, the presented workflow demonstrates that high-resolution, non-targeted LC-MS metabolic profiling is perfectly suited to satisfy the characterization of temporary tattoo and hair dye samples.

There are several reasons that make this a topic of current relevance as due to its availability on Internet sites, the use of temporary tattoos and dyes continues to increase as a substitute for permanent ones. The improvement of related issues such as correct labeling of ingredients and their concentrations is necessary. The lack of such information can enhance the appearance of more allergic reactions to be considered with their use. It is also required to establish the regulation of these products.

Author Contributions: Conceptualization, C.G.-J. and M.L.; methodology, L.R.; software, L.R.; validation, M.L. and L.R.; formal analysis, L.R.; investigation, L.R.; resources, C.G.-J. and M.L.; data curation, C.G.-J., M.L. and L.R.; writing-original draft preparation, L.R.; writing-review and editing, C.G.-J. and M.L.; visualization, M.L.; supervision, C.G.-J. and M.L.; project administration, M.L.; funding acquisition, C.G.-J. and M.L. All authors have read and agreed to the published version of the manuscript.

Funding: This research received no external funding. 
Acknowledgments: This research was supported by projects EQC2018-005011-P (Ministry of Science, Innovation and Universities, Spain) and ED431 2020/06 (Xunta de Galicia). The authors belong to the CRETUS Strategic Partnership (ED431E 2018/01). All these programs are co-funded by FEDER (UE). L.R. acknowledges Xunta de Galicia for her predoctoral contract (ED481A-2018/227).

Conflicts of Interest: The authors declare no conflict of interest.

\section{References}

1. Kazandjieva, J.; Grozdev, L.; Tsankov, N. Temporary henna tattoos. Clin. Dermatol. 2007, 25, 383-387. [CrossRef] [PubMed]

2. Rubio, L.; Guerra, E.; Garcia-Jares, C.; Lores, M. Body-decorating products: Ingredients of permanent and temporary tattoos from analytical and european regulatory perspectives. Anal. Chim. Acta 2019, 1079, 59-72. [CrossRef] [PubMed]

3. Almeida, P.J.; Borrego, L.; Pulido-Melian, E.; Gonzalez-Diaz, O. Quantification of p-phenylenediamine and 2-hydroxy-1,4naphthoquinone in henna tattoos. Contact Dermat. 2012, 66, 33-37. [CrossRef]

4. Aktas Sukuroglu, A.; Battal, D.; Burgaz, S. Monitoring of lawsone, p-phenylenediamine and heavy metals in commercial temporary black henna tattoos sold in Turkey. Contact Dermat. 2017, 76, 89-95. [CrossRef] [PubMed]

5. Scientific Committee on Consumer Safety (SCCS) Opinion on Lawsonia Inermis (Henna) COLIPA n_C169, 19 September 2013 SCCS/1511/13. Available online: https://ec.europa.eu/health/scientific_committees/consumer_safety/docs/sccs_o_140.pdf (accessed on 20 May 2021).

6. Waton, J.; Brault, F.; Laveine, E. A putative case of allergic contact dermatitis caused by a jagua tattoo. Contact Dermat. 2017, 76 , 296-321. [CrossRef]

7. Maarouf, M.; Saberian, C.; Segal, R.J.; Shi, V.Y. A new era for tattoos, with new potential complications. J. Clin. Aesthet. Dermatol. 2019, 12, 37-38. [PubMed]

8. Bircher, A.J.; Sigg, R.; Hofmeier, K.S.; Schlegel, U.; Hauri, U. Allergic contact dermatitis caused by a new temporary blue-black tattoo dye- sensitization to genipin from jagua (Genipa Americana L.) fruit extract. Contact Dermat. 2017, 77, 374-378. [CrossRef] [PubMed]

9. Manual of the Working Group on Cosmetic Products (Sub-Group on Borderline Products) on the Scope of Application of the Cosmetics Regulation (EC) No 1223/2009 (Art. 2(1)(A)) Version 3.1. 2017. Available online: https://ec.europa.eu/docsroom/ documents / 29002 (accessed on 20 May 2021).

10. Regulation (EC) No 1223/2009 of the European Parliament and of the Council of 30 November 2009 on Cosmetic Products (Recast). Off. J. Eur. Union L 2009, 342, 59.

11. Directive 2009/48/EC of the European Parliament and of the Council of 18 June 2009 on the Safety of Toys. Off. J. Eur. Union L 2009, 170, 1-37.

12. Lores, M.; Celeiro, M.; Rubio, L.; Llompart, M.; Garcia-Jares, C. Extreme cosmetics and borderline products: An analytical-based survey of European regulation compliance. Anal. Bioanal. Chem. 2018, 410, 7085-7102. [CrossRef]

13. Rubio, L.; Lores, M.; Garcia-Jares, C. Monitoring of natural pigments in henna and jagua tattoos for fake detection. Cosmetics 2020, 7, 74. [CrossRef]

14. Alvarez-Rivera, G.; Ballesteros-Vivas, D.; Parada-Alfonso, F.; Ibañez, E.; Cifuentes, A. Recent applications of high resolution mass spectrometry for the characterization of plant natural products. Trends Anal. Chem. 2019, 112, 87-101. [CrossRef]

15. Wolfender, J.-L.; Marti, G.; Thomas, A.; Bertrand, S. Current approaches and challenges for the metabolite profiling of complex natural extracts. J. Chromatogr. A 2015, 1382, 136-164. [CrossRef]

16. Zhang, A.; Sun, H.; Yan, G.; Wang, X. Recent developments and emerging trends of mass spectrometry for herbal ingredients analysis. Trends Anal. Chem. 2017, 94, 70-76. [CrossRef]

17. Ruttkies, C.; Schymanski, E.L.; Wolf, S.; Hollender, J.; Neumann, S. MetFrag relaunched: Incorporating strategies beyond in silico fragmentation. J. Cheminform. 2016, 8, 3. [CrossRef]

18. Wolf, S.; Schmidt, S.; Müller-Hannemann, M.; Neumann, S. In silico fragmentation for computer assisted identification of metabolite mass spectra. BMC Bioinform. 2010, 11, 148. [CrossRef]

19. Calderón-Santiago, M.; Priego-Capote, F.; Luque De Castro, M.D. Enhanced detection and identification in metabolomics by use of LC-MS/MS untargeted analysis in combination with gas-phase fractionation. Anal. Chem. 2014, 86, 7558-7565. [CrossRef]

20. Ríos, J.J.; Roca, M.; Pérez-Gálvez, A. Systematic HPLC/ESI-high resolution-qTOF-MS methodology for metabolomic studies in nonfluorescent chlorophyll catabolites pathway. J. Anal. Methods Chem. 2015, 2015, 1-10. [CrossRef]

21. Cosmetic Ingredient Database. Available online: https:/ /ec.europa.eu/growth/sectors/cosmetics/cosing_en (accessed on 20 May 2021).

22. Scientific Committee on Consumer Safety Opinion (SCCS) on Fragrance Allergens in Cosmetic Products, 26-27 June 2012 SCCS/1459/11. Available online: https:/ /ec.europa.eu/health/scientific_committees/consumer_safety/docs/sccs_o_102.pdf (accessed on 20 May 2021).

23. Guerra, E.; Llompart, M.; Garcia-Jares, C. Miniaturized matrix solid-phase dispersion followed by liquid chromatoraphy-tandem mass spectrometry for the quantification of synthetic dyes in cosmetics and foodstuffs used or consumed by children. J. Chromatogr. A 2017, 1529, 29-38. [CrossRef] [PubMed]

24. Horai, H.; Arita, M.; Kanaya, S.; Nihei, Y.; Ikeda, T.; Suwa, K.; Nishioka, T. MassBank: A public repository for sharing mass spectral data for life sciences. J. Mass Spectrom. 2010, 45, 703-714. [CrossRef] [PubMed] 
25. Tsugawa, H.; Cajka, T.; Kind, T.; Ma, Y.; Higgins, B.; Ikeda, K.; Kanazawa, M.; VanderGheynst, J.; Fiehn, O.; Arita, M. MS-DIAL: Data-independent MS/MS deconvolution for comprehensive metabolome analysis. Nat. Methods 2015, 2, 523-526. [CrossRef]

26. Folashade, K.O.; Omoregie, E.H. Chemical constituents and biological activity of medicinal plants used for the management of sickle cell disease-A review. J. Med. Plant Res. 2013, 7, 3452-3476.

27. Semwal, R.B.; Semwal, D.K.; Combrinck, S.; Cartwright-Jones, C.; Viljoen, A. Lawsonia inermis L. (henna): Ethnobotanical, phytochemical and pharmacological aspects. J. Ethnopharmacol. 2014, 155, 80-103.

28. Chaudhary, G.; Goyal, S.; Poonia, P. Lawsonia inermis Linnaeus: A phytopharmacological review. Int. J. Pharm. Sci. Drug Res. 2010, 2, 91-98.

29. Scientific Committee on Consumer Safety Opinion (SCCS) on Acid Orange 7, 18 June 2014, SCCS/1536/14, Revision of 23 September 2014. Available online: https:/ / ec.europa.eu/health/sites/default/files/scientific_committees/consumer_safety/ docs/sccs_o_158.pdf (accessed on 20 May 2021).

30. Labyad, N.; Aljele, S. Pharmacognostic and phytochemical study of hair dyes henna in Libyan market. IJPSAT 2020, 21, 239-244.

31. Dweck, A.C. Natural ingredients for colouring and styling. Int. J. Cosmetic Sci. 2002, 24, 287-302. [CrossRef] 